\title{
Norepinephrine Modulates Glutamatergic Transmission in the Bed Nucleus of the Stria Terminalis
}

\author{
Regula E Egli', Thomas L Kash', Kevin Choo', Valentina Savchenko², Robert T Matthews ${ }^{3}$, \\ Randy D Blakely ${ }^{2,4}$ and Danny G Winder*,, 2,4 \\ 'Department of Molecular Physiology and Biophysics, Vanderbilt University School of Medicine, Nashville, TN, USA; ${ }^{2}$ Center for Molecular \\ Neuroscience, Vanderbilt University School of Medicine, Nashville, TN, USA; ${ }^{3}$ Department of Anatomy, Meharry Medical College, USA; \\ ${ }^{4}$ JF Kennedy Center for Research on Human Development, Vanderbilt University School of Medicine, Nashville, TN, USA
}

\begin{abstract}
The bed nucleus of the stria terminalis (BNST) and its adrenergic input are key components in stress-induced reinstatement and maintenance of drug use. Intra-BNST injections of either $\beta$-adrenergic receptor ( $\beta$-AR) antagonists or $\alpha_{2}$-adrenergic receptor $\left(\alpha_{2}\right.$-AR) agonists can inhibit footshock-induced reinstatement and maintenance of cocaine- and morphine-seeking. Using electrophysiological recording methods in an in vitro slice preparation from C57/BI6j adult male mouse BNST, we have examined the effects of adrenergic receptor activation on excitatory synaptic transmission in the lateral dorsal supracommissural BNST (dBNST) and subcommissural BNST (vBNST). $\alpha_{2}$-AR activation via UK-I4,304 (I0 $\mu$ M) results in a decrease in excitatory transmission in both dBNST and VBNST, an effect predominantly dependent upon the $\alpha_{2 A}$-AR subtype. $\beta$-AR activation via isoproterenol $(I \mu M)$ results in an increase in excitatory transmission in $\mathrm{dBNST}$, but not in vBNST. Consistent with the work with receptor subtype specific agonists, application of the endogenous ligand norepinephrine (NE, I00 $\mu \mathrm{M}$ ) elicits two distinct effects on glutamatergic transmission. In dBNST, NE elicits an increase in transmission (62\% of dBNST NE experiments) or a decrease in transmission (38\% of dBNST NE experiments). In vBNST, NE elicits a decrease in transmission in 100\% of the experiments. In dBNST, the NE-induced increase in synaptic transmission is blocked by $\beta_{1} / \beta_{2^{-}}$and $\beta_{2^{-}}$, but not $\beta_{1}$-specific antagonists. In addition, this increase is also reduced by the $\alpha_{2}$-AR antagonist yohimbine and is absent in the $\alpha_{2 A}-A R$ knockout mouse. In VBNST, the NE-induced decrease in synaptic transmission is markedly reduced in the $\alpha_{2 A}-A R$ knockout mouse. Further experiments demonstrate that the actions of NE on glutamatergic transmission can be correlated with $\beta$-AR function.

Neuropsychopharmacology (2005) 30, 657-668, advance online publication, I5 December 2004; doi: I0.1 038/sj.npp. 1300639
\end{abstract}

Keywords: BNST; electrophysiology; norepinephrine; $\beta$-AR; $\alpha_{2}-A R$; addiction

\section{INTRODUCTION}

Clinical studies indicate that stress is a key driving force in addiction, providing a strong stimulus for relapse to drugand alcohol-seeking (Brown et al, 1995; Le et al, 2000; Sinha et al, 1999). Reinstatement of drug- and alcohol-seeking can be modeled in rodents using behavioral paradigms such as stress-induced reinstatement of both conditioned place preference (Wang et al, 2001) and self-administration (Shaham et al, 2000). The noradrenergic system in the

\footnotetext{
*Correspondence: Dr DG Winder, Department of Molecular Physiology and Biophysics, Vanderbilt University School of Medicine, Room 724B, MRB I, 23rd and Pierce Ave, Nashville, TN 37232-06 I5, USA, Tel: + 615322 II44, Fax: + 615322 I462,

E-mail: danny.winder@vanderbilt.edu

Received 9 September 2004; revised 3 November 2004; accepted 8 November 2004

Online publication: 10 November 2004 at http://www.acnp.org/citations/ Npp I | | 004040408/default.pdf
}

brain is a key mediator of the stress response and plays a critical role in stress-induced reinstatement. Peripheral administration of blood-brain-barrier permeant, but not impermeant, $\alpha_{2}$-adrenergic receptor $\left(\alpha_{2}\right.$-AR) agonists blocks footshock-induced reinstatement of heroin-seeking in rats (Erb et al, 2000). Further, lesioning the ventral noradrenergic bundle (VNAB), one of the two primary sources of NE in the brain, results in the inhibition of footshock-induced reactivation of morphine-seeking (Wang et al, 2001), as well as blockade of opiate withdrawal-induced conditioned place aversion (Delfs et al, 2000).

The anterolateral bed nucleus of the stria terminalis (BNST) is one of the major targets of the VNAB, receiving one of the densest noradrenergic inputs in the brain. IntraBNST injection of $\beta$-AR antagonists or $\alpha_{2}$-AR agonists prevents morphine withdrawal-induced conditioned place aversion (Delfs et al, 2000) and also blocks stress-induced reinstatement of cocaine-seeking (Leri et al, 2002), as well as stress-induced reinstatement of morphine-conditioned place preference (Wang et al, 2001). 
Comparatively few studies have examined the excitable properties of neurons within the BNST (Rainnie, 1999; Egli and Winder, 2003; Weitlauf et al, 2004), and even less is known of the mechanisms of noradrenergic regulation of the function of these neurons. Here we examine the noradrenergic innervation of adult mouse BNST as well as the effect of noradrenergic receptor activation on glutamatergic transmission recorded from an in vitro slice preparation of adult mouse BNST. We find that, consistent with the rat and primate literature (Freedman and Shi, 2001; Georges and Aston-Jones, 2001; Woulfe et al, 1990), the adrenergic innervation of the mouse anterolateral BNST is predominantly to the subcommissural, or ventral BNST (vBNST). Interestingly, we find two opposing actions of $\beta_{2^{-}}$and $\alpha_{2 A^{-}}$ARs on glutamatergic transmission: NE can enhance glutamatergic transmission, acting predominantly through the $\beta_{2}$ - and $\alpha_{2}$-ARs, as well as depress glutamatergic transmission via activation of the $\alpha_{2 \mathrm{~A}}$-AR. In total, our data suggest a potential mechanism underlying the effects of administration of adrenergic ligands into the BNST on reinstatement of drug-seeking behavior.

\section{MATERIALS AND METHODS}

\section{Animal Care}

All animals were housed in the Vanderbilt Animal Care Facilities in groups of 2-5. Food and water were available ad libitum.

\section{Immunofluorescence Detection of the NE Transporter in Brain Sections}

The NE transporter (NET) 43408 rabbit polyclonal antibody that has been previously described (Savchenko et al, 2003) detects a peptide sequence located in the second extracellular loop of mouse NET and was used for establishing noradrenergic fiber distribution in the dorsal and ventral BNST. The secondary antibody used was a donkey antirabbit IgG conjugated with CY3 (Jackson ImmunoResearch Laboratories, Inc., West Grove, PA, 1:1000); cells were counterstained with NeuroTrace 640/660 deep red-fluorescent Nissl (Molecular Probes Inc., Eugene, OR, 1:1000).

Adult C57B1/6 mice (Harlan, Indianapolis, IN) were used. Knockout mice, bearing a targeted deletion of the first coding exon of the NET gene, were provided by Dr Marc Caron (HHMI, Duke University School of Medicine). Mice were deeply anesthetized with Nembutal $(80 \mathrm{mg} / \mathrm{kg})$, heparinized $(1000 \mathrm{U} / \mathrm{kg})$, and transcardially perfused with saline containing heparin, followed by Prefer fixative (Anatech, Ltd, Battle Creek, MI). After perfusion for $30 \mathrm{~min}$, brains were removed and immersed in fixative $4 \mathrm{~h}$ at room temperature and then cryoprotected in 30\% sucrose overnight at $4{ }^{\circ} \mathrm{C}$. Floating frozen sections $(20 \mu \mathrm{M})$ were cut into TRIS-buffered saline (TBS) using a sledge microtome (Leica Microsystems, Bannockburn, IL) and then incubated sequentially with primary antibody overnight and secondary antibodies $1 \mathrm{~h}$ at room temperature. Nonspecific binding was blocked by incubation in TBS containing $4 \%$ normal donkey serum (NDS; Jackson ImmunoResearch Laboratories, Inc., West Grove, PA) and 0.2\% Triton X-100 for $1 \mathrm{~h}$ prior to incubations with rabbit polyclonal NET

43408 antibody containing 2\% NDS and 0.2\% Triton X-100. Immunofluorescence was visualized using a Zeiss Axiovert S100 outfitted for fluorescence optics or a Zeiss Axioplan 2 confocal imaging system equipped with internal $\mathrm{He} / \mathrm{Ne}$ and external Ar/Kr lasers (VUMC Cell Imaging Core Resource) with output at 568 (CY3) and 640 (CY5) nm. Z-Series images were collected by optical sectioning at intervals of $1 \mu \mathrm{m}$ followed in some cases by $3 \mathrm{D}$ reconstruction. Image processing and montage assembly were performed using Adobe Photoshop.

\section{Field Recording}

Male C57Bl/6 mice (5-10 weeks old, The Jackson Laboratory, Bar Harbor, ME) were taken from the animal facilities and individually housed for $1 \mathrm{~h}$ prior to being anesthetized with isoflurane and killed via decapitation. The brains were quickly removed and placed in ice-cold artificial cerebrospinal fluid (ACSF) (in mM: $124 \mathrm{NaCl}, 4.4 \mathrm{KCl}, 2 \mathrm{CaCl}_{2}, 1.2$ $\mathrm{MgSO}_{4}, 1 \mathrm{NaH}_{2} \mathrm{PO}_{4}, 10$ glucose, and $\left.26 \mathrm{NaHCO}_{3}\right)$. Slices containing the BNST (Bregma 0.26-0.14 mm (Franklin and Paxinos, 1997, Figure 1a) $350 \mu \mathrm{m}$ in thickness were prepared using a vibratome (Ted Pella, Redding, CA). Slices were then transferred to a recording chamber where they were
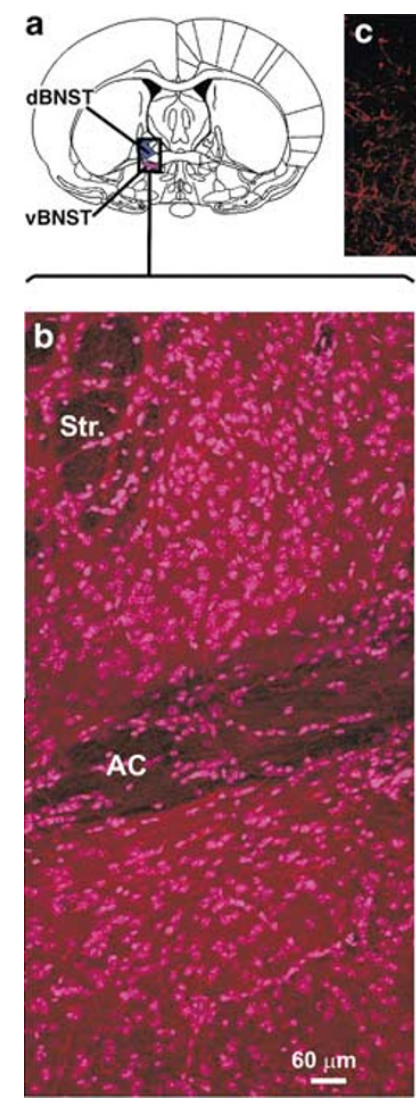

Figure I NET labeling in C57B16/J mouse BNST. (a) Schematic adapted from Franklin and Paxinos mouse brain atlas showing dBNST (blue) and vBNST (purple). (b) NET (red fibers)/Nissl (pink puncta) double-labeling in dBNST and vBNST $(20 \times$ magnification). (c) NET labeling (red) in vBNST from wild-type mouse $(40 \times$ magnification). (d) NET labeling (red) in vBNST from NET knockout mouse $(40 \times$ magnification). (e) NET labeling (red) in dBNST $(40 \times$ magnification). ( $f$ ) NET labeling (red) in vBNST $(40 \times$ magnification) (str. $=$ striatum, $A C=$ anterior commissure). 
perfused with heated $\left(\sim 28^{\circ} \mathrm{C}\right)$ oxygenated $\left(95 \% \quad \mathrm{O}_{2} / 5 \%\right.$ $\mathrm{CO}_{2}$ ) ACSF at a rate of $2 \mathrm{ml} / \mathrm{min}$. Slices were allowed to equilibrate in normal ACSF for $1 \mathrm{~h}$ before experiments began. In all experiments, including the whole-cell patch and sharp intracellular recordings described below, after the $1 \mathrm{~h}$ recovery time the $\mathrm{GABA}_{\mathrm{A}} \mathrm{R}$ antagonist picrotoxin $(25 \mu \mathrm{M})$ was included in the bath to block inhibitory transmission. Recording electrodes were pulled on a Flaming-Brown Micropipette Puller (Sutter Instruments, Novato, CA) using thin-walled borosilicate glass capillaries.
Electrodes were filled with ACSF and had resistances of approximately 1-3 M $\Omega$. The recording electrode and a bipolar nichrome wire stimulating electrode were placed locally within the BNST $\sim 500 \mu \mathrm{m}$ away from one another to elicit a local field response. A suitable response with distinguishable $\mathrm{N} 1$ and $\mathrm{N} 2$ components was found. The response was analyzed by measuring the amplitude of $\mathrm{N} 2$, the synaptic component of the response (Figure 2a, b). An input/output curve was obtained by administering a range of stimulation intensities, beginning with $3 \mathrm{~V}$ and increasing

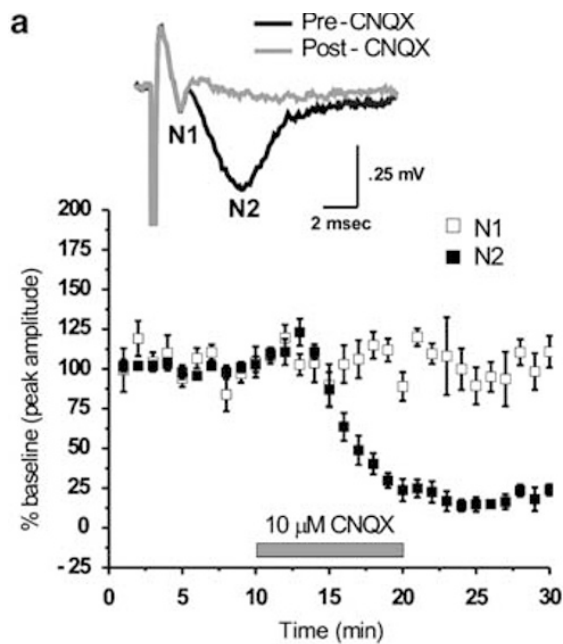

b
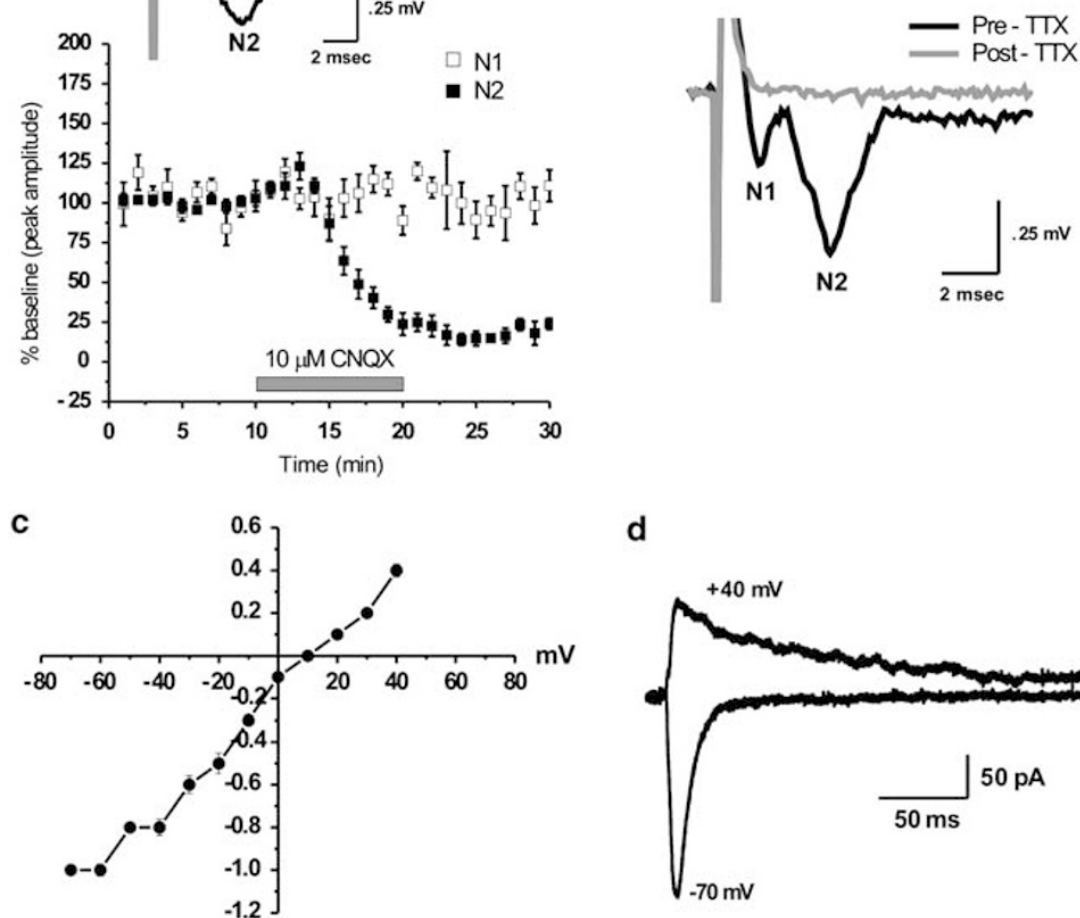

d

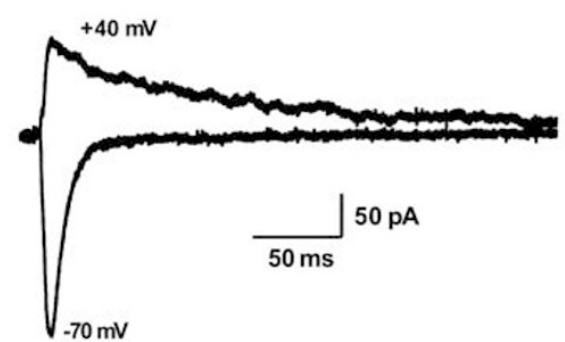

Normalized Current Amplitude

e

dBNST
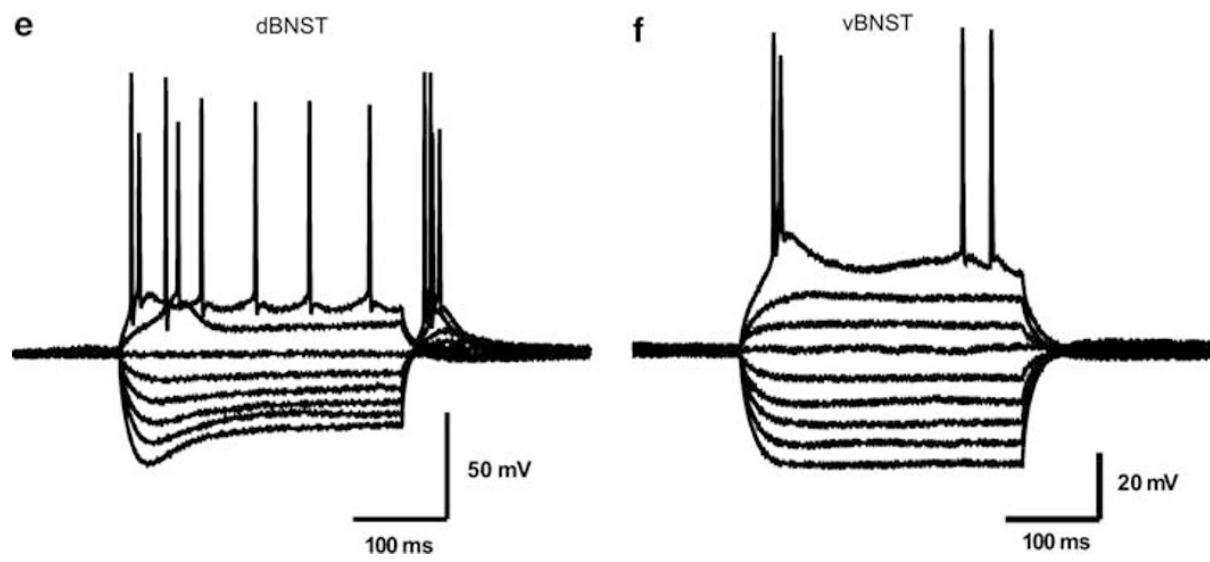

Figure 2 Characterization of extracellular field potentials and whole-cell patch clamp recordings in the BNST. (a) The AMPAR antagonist CNQX (I $0 \mu M$ ) completely blocked the second negative deflection (N2) in the field potential without affecting the first negative deflection (NI). (b) The $\mathrm{Na}^{+}$channel blocker TTX $(\mathrm{I} \mu \mathrm{M})$ blocked both the NI and the N2. (c) Normalized current-voltage relationship of synaptically evoked EPSCs in BNST neurons. Data are not corrected for junction potential $(\sim 12.7 \mathrm{mV}$ ). (d) Representative traces of EPSCs analyzed in (c). (e-f) Voltage responses to current injection in currentclamp mode for a dBNST neuron (e) and a vBNST neuron ( $f$. 
in increments of $2 \mathrm{~V}$ until the maximum amplitude response was obtained. The maximum stimulus intensity that was administered was $25 \mathrm{~V}$. A stable baseline was obtained by delivering a stimulus at an intensity that evoked a response that was approximately half maximal once every $20 \mathrm{~s}$ for at least $20 \mathrm{~min}$. Once a baseline was obtained, drug application experiments were performed as described. All drugs (except for picrotoxin, which was present in the bath ACSF at all times) were applied at a $10 \times$ concentration at a $1 / 10$ flow rate using a syringe pump (Harvard Apparatus, Holliston, MA). In pilot vehicle applications, we found that the slight increase in flow rate induced by this manner of drug application had no effect on basal responses (data not shown). Using dye, we estimate that drug solutions infuse the recording chamber $\sim 3-5$ min after turning drug pump on.

\section{Visualized Whole-Cell Patch Clamp Recording}

Animals were prepared as described for field recordings with the following exceptions: after removal from the animal, the brain was placed in ice-cold low $\mathrm{Na}^{+} /$high sucrose ACSF (in mM: 194 sucrose, $30 \mathrm{NaCl}, 4.5 \mathrm{KCl}, 1.0$ $\mathrm{MgCl}_{2}, 1.2 \mathrm{NaH}_{2} \mathrm{PO}_{4}, 10$ glucose, and $\left.26 \mathrm{NaHCO}_{3}\right)$. Slices $300 \mu \mathrm{m}$ in thickness were prepared using a vibratome (Leica Microsystems, Bannockburn, IL). Slices were then transferred to a submerged recording chamber where they were perfused with heated $\left(\sim 28^{\circ} \mathrm{C}\right)$ oxygenated $\left(95 \% \quad \mathrm{O}_{2} / 5 \%\right.$ $\mathrm{CO}_{2}$ ) normal (non-sucrose) picrotoxin $(25 \mu \mathrm{M})$ ACSF at a rate of $2 \mathrm{ml} / \mathrm{min}$. Electrodes of $\sim 3.5-5.0 \mathrm{M} \Omega$ were pulled on a Flaming-Brown Micropipette Puller (Sutter Instruments, Novato, CA) and were filled with (in mM): $110.0 \mathrm{CsMeSO}_{4}$, 20.0 CsCl, 10.0 HEPES, 0.6 EGTA, 2.5 $\mathrm{MgCl}_{2}, 4.0 \mathrm{Na}_{2} \mathrm{ATP}$, $0.4 \mathrm{NaGTP}$ and neurobiotin $(0.2 \% \mathrm{w} / \mathrm{v})$. Junction potential, as calculated using Clampex 9.2, was $\sim 12.7 \mathrm{mV}$, and is uncorrected in the data presented. All cells recorded from were held at $-70 \mathrm{mV}$. Input resistance values ranged from 173-1114 M $\Omega$ (average \pm SEM: $408.5 \pm 89.1 \mathrm{M} \Omega$ ). Series resistance values ranged from 3.0 to $21.6 \mathrm{M} \Omega$. Excitatory postsynaptic currents (EPSCs) of 100-200 pA were recorded and input resistance, holding current, series resistance were all monitored continuously throughout the duration of the experiments. All drugs were bath-applied at their final concentrations. Based on dye experiments, we estimate that drug infuses the recording chamber within $2 \mathrm{~min}$ of switching to drug solution.

\section{Intracellular Recording}

Brain slices were prepared as described for field recordings, except that the ACSF flow rate in the interface chamber was $1.0-1.3 \mathrm{ml} / \mathrm{min}$. Recording electrodes were pulled on a Flaming-Brown Micropipette Puller (Sutter Instruments, Novato, CA) using thick-walled filament-containing borosilicate glass capillaries. Electrodes were filled with $2 \mathrm{M}$ potassium acetate and were of approximately $120-170 \mathrm{M} \Omega$ resistance. A current/voltage relationship from each cell was obtained by injecting a range of current via the recording electrode. A bipolar nichrome wire stimulating electrode was placed locally within the BNST $\sim 500 \mu \mathrm{m}$ from the recording electrode. An input/output curve of synaptic responses was generated by stimulating with a range of input voltages with stimulus durations from 50 to $100 \mu \mathrm{s}$, starting at $3 \mathrm{~V}$ and increasing the stimulus in $2 \mathrm{~V}$ increments until the cell fired an action potential (AP). If the cell did not fire, the maximum stimulus intensity administered was $35 \mathrm{~V}$. IR was monitored throughout the duration of the experiment by injecting a current pulse at the end of each stimulus test pulse. Drug delivery was performed as during field recording experiments.

\section{Pharmacology}

Propranolol, clonidine, picrotoxin, norepinephrine, UK14,304, timolol, baclofen and isoproterenol were purchased from Sigma (St Louis, MO). Betaxolol and ICI-118,551 were purchased from Tocris (Ellisville, MO). DMSO was the carrier for picrotoxin $(0.02 \% \mathrm{v} / \mathrm{v})$, UK-14,304 and ICI$118,551(0.1 \% \mathrm{v} / \mathrm{v})$.

\section{Data Analysis}

Electrophysiological data was collected and analyzed using pClamp 9.0 software (Axon Instruments, Union City, CA). Field and whole-cell patch clamp synaptic transmission experiments were analyzed by measuring the peak amplitude of the synaptic response which was normalized and averaged across at least three experiments for each manipulation using Excel. Sharp microelectrode intracellular experiments were analyzed by measuring the slope of the synaptic response, which was normalized and averaged across at least three experiments using Excel. Statistical analyses (paired $t$-test, unless otherwise noted) were performed using Prizm and InStat software. All values given for drug effects throughout the paper are normalized and presented as average \pm SEM relative to predrug values. Predrug values for statistical analyses of field experiments were taken from the 5 min immediately preceding application of the drug. Postdrug values for adrenergic agonist experiments were taken at the peak effect of the drug for each individual experiment. For the dBNST NE experiments where the effect was a rise in transmission, this time point was a 5-min block beginning $4 \mathrm{~min}$ after $\mathrm{NE}$ application began. For experiments where NE caused a decrease in transmission (both dBNST and vBNST), this time point was a 5-min block beginning $9 \mathrm{~min}$ after NE application began. For the long-term depression time point in the dBNST NEdecrease experiments, a 5-min block beginning $30 \mathrm{~min}$ after NE application was terminated was used. For all dBNST antagonist co-application experiments, the postdrug effect values were taken from a 5-min period beginning $4 \mathrm{~min}$ after NE application began (the same time point as NE alone experiments), allowing comparison between effects of $\mathrm{NE}$ in the presence and absence of various adrenergic receptor antagonists. For all isoproterenol experiments, postdrug values were taken from a 5-min time period beginning $16 \mathrm{~min}$ after isoproterenol application began. Postdrug values for UK-14,304 field experiments were taken from a 5-min time period beginning $10 \mathrm{~min}$ after UK-14,304 application terminated. For analysis of patch-clamp experiments, predrug values were taken from the 5 min immediately preceding drug application. Postdrug values for UK-14,304 patch-clamp experiments were taken from a 
5-min time period beginning immediately after drug application was terminated.

\section{RESULTS}

\section{Distribution of NET-Positive Fibers}

Previous studies in the rat and primate demonstrated that noradrenergic innervation of vBNST is significantly greater than dBNST (Freedman and Shi, 2001; Georges and AstonJones, 2001; Woulfe et al, 1990). To determine whether this pattern of innervation is conserved in the mouse, we used a previously characterized antibody generated against the norepinephrine transporter (NET) (Savchenko et al, 2003). NET immunoreactive fibers were observed in both the dorsal and ventral BNST in wild type (Figure 1b, c, e, f), but not NET-knockout mice (Figure 1d). Consistent with rat and primate data, the staining for NET was denser in vBNST (Figure 1f) than in dBNST (Figure 1e). Nissl counterstaining revealed dense cellular distribution in both dBNST and vBNST (Figure 1b).

\section{BNST Extracellular Field Potential}

To begin to study the effects of $\mathrm{NE}$ on glutamatergic synaptic transmission in the BNST, extracellular field potential recordings were obtained from acutely prepared BNST slices in an interface recording chamber. As previously reported (Weitlauf et al, 2004), this field potential has two negative peaks. The second peak, but not the first, is sensitive to the glutamatergic receptor antagonist CNQX $(10 \mu \mathrm{M})$, indicating that the second peak is due to glutamatergic synaptic transmission (Figure 2a). Both peaks can be blocked using the $\mathrm{Na}^{+}$channel blocker tetrodotoxin (TTX, $1 \mu \mathrm{M}$ ) (Figure $2 \mathrm{~b}$ ), suggesting that the first peak is due to axonal AP firing. These two peaks have been designated as $\mathrm{N} 1$ (the first negative peak) and N2 (the second negative peak) based on terminology from the striatal field potential literature (Cordingley and Weight, 1986; Malenka and Kocsis, 1988; Takagi and Yamamoto, 1978). Given the latency of the response and pharmacology indicating that the $\mathrm{N} 2$ peak is driven by glutamatergic receptor activation, the peak amplitude of the N2 was measured as an extracellular estimate of postsynaptic responses driven by excitatory glutamatergic synaptic transmission.

\section{Single-Cell Analysis of Glutamatergic Transmission in Anterolateral BNST}

In addition to utilizing extracellular recordings to assess the actions of adrenergic receptors on glutamatergic synaptic transmission, we also employed single-cell recording approaches. We found, as we previously reported (Egli and Winder, 2003), that robust AMPA-receptor mediated excitatory postsynaptic potentials (EPSPs) could be recorded using sharp microelectrodes (Figure $4 \mathrm{~b}$, inset). Further, using whole-cell patch clamp recording techniques in the voltage clamp configuration, we could isolate EPSCs (Weitlauf et al, 2004; Figure 2c, d). The EPSCs were blocked by the AMPA receptor antagonist CNQX (data not shown), and, with correction for junction potential $(\sim 12.7 \mathrm{mV})$, these EPSCs reversed very near $0 \mathrm{mV}$ (Figure 2c), consistent with their mediation by ionotropic glutamate receptors and suggesting that reasonable voltage control is occurring. Finally, in current clamp recordings in the whole-cell patch clamp configuration, current-voltage relationships suggest that overlapping populations of neurons are sampled with the sharp microelectrode and whole-cell patch approaches, as, similar to the previous data (Egli and Winder, 2003), we find that many neurons sampled using whole-cell configuration in the dBNST express hyperpolarization-activated current activity, while many cells in the vBNST display a low threshold spike (Figure 2e, f).

\section{$\alpha_{2 \mathrm{~A}}-\mathrm{AR}$ Activation Decreases Excitatory Transmission}

Using extracellular recordings, we find that 10-15-min bath application of the $\alpha_{2}$-AR agonist UK-14,304 (1-10 $\left.\mu \mathrm{M}\right)$ elicited a marked decrease in N2 amplitude in both dBNST $(10 \mu \mathrm{M}, \quad 10-\mathrm{min}$ application: $41.7 \pm 7.7 \%$ of baseline, $p<0.05, n=3$, Figure $3 \mathrm{a}$, black squares; $10 \mu \mathrm{M}, 15$-min application: $31.7 \pm 7.1 \%, p<0.05, n=6$ (data not shown); $1 \mu \mathrm{M}, 15$-min application: $63.1 \pm 11.2 \%, p<0.05, n=6$ (data not shown); and vBNST $(10 \mu \mathrm{M}, 10$-min application, $42.5 \pm 5.7 \%, p<0.001, n=5$, Figure $3 b$ ). Similar results were also seen using clonidine $(1 \mu \mathrm{M})$, another $\alpha_{2}$-AR agonist (data not shown). To begin to determine the locus of $\alpha_{2}$-AR mediated effects on glutamatergic transmission, whole-cell patch clamp recordings were performed from dBNST and vBNST cells in slices from adult wild-type mice. Application of 1-10 $\mu \mathrm{M}$ UK-14,304 dramatically decreased the EPSC amplitude in both dBNST and vBNST similarly to that seen in extracellular field recordings (dBNST $21.5 \pm 3.7 \%$ of baseline, $p<0.0001, n=5$, Figure $3 c$, e; vBNST $33.2 \pm 7.3, p<0.05, n=4$, Figure $3 \mathrm{~d}$ ). The decrease in glutamatergic transmission seen with UK-14,304 was associated with a significant increase in the PPF ratio in dBNST, consistent with a presynaptic effect on glutamatergic synaptic transmission $(156.7 \pm 14.3 \%, p<0.05$, inset Figure 3c). A modest but significant increase in input resistance accompanied the decrease in EPSC amplitude in dBNST $(123.5 \pm 4.4 \%$ of predrug input resistance, $p<0.05$, data not shown), but there was no consistent change in holding current (data not shown). Curiously, in the vBNST recordings, no changes were observed in paired-pulse ratio $(115 \pm 17 \%$ of predrug values, inset Figure $3 \mathrm{~d}$ ) or in input resistance $(96 \pm 5 \%$ of predrug value, data not shown) although a trend towards an increased paired-pulse ratio was observed.

To determine the subtype of $\alpha_{2}$-AR involved in these responses, we assessed the effects of UK-14,304 on glutamatergic synaptic responses in BNST slices prepared from $\alpha_{2 \mathrm{~A}}$-AR knockout mice. Bath application of $10 \mu \mathrm{M}$ UK14,304 resulted in no alteration of N2 amplitude in dBNST in $\alpha_{2 \mathrm{~A}}$-AR knockout mice $(102.2 \pm 3.5 \%, n=7$, Figure $3 \mathrm{a}$, white squares), indicating that the $\alpha_{2 \mathrm{~A}}$-AR subtype is required for the bulk of the $\alpha_{2}-\mathrm{AR}$ mediated effects on glutamatergic synaptic responses in dorsal anterolateral BNST. The $\mathrm{GABA}_{\mathrm{B}} \mathrm{R}$ agonist baclofen $(30 \mu \mathrm{M})$ elicited a robust reduction in the $\mathrm{N} 2(35.2 \pm 4.2 \%$ of baseline, $p<0.05$, data not shown), indicating that $\mathrm{G}_{\mathrm{i} / \mathrm{o}}$-linked signaling still occurs in these mice. In vBNST, we assessed the actions of UK-14,304 on evoked EPSCs in the knockout mouse. As in 
a

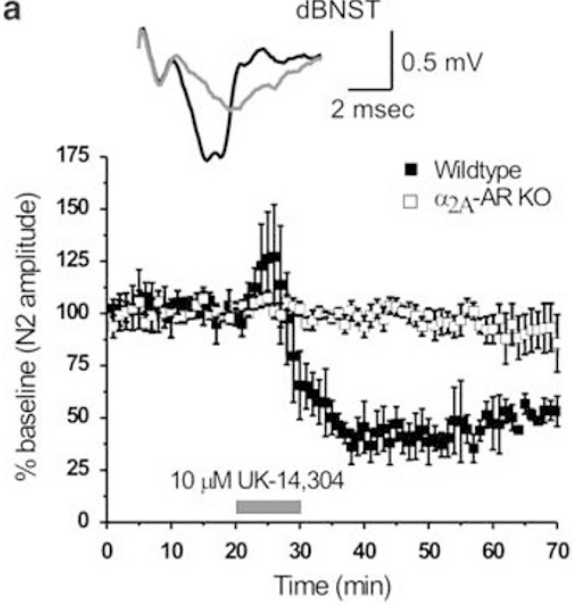

C

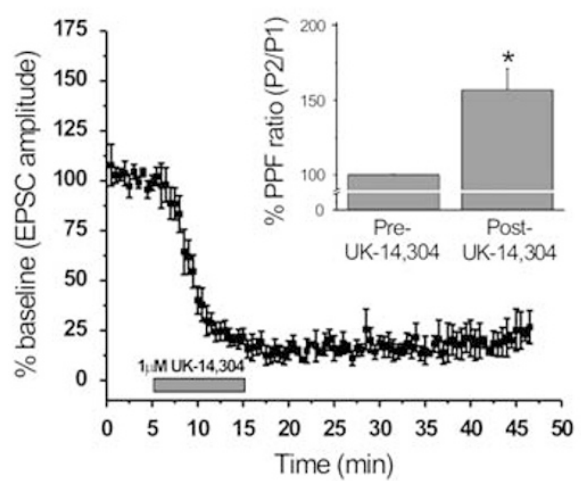

e
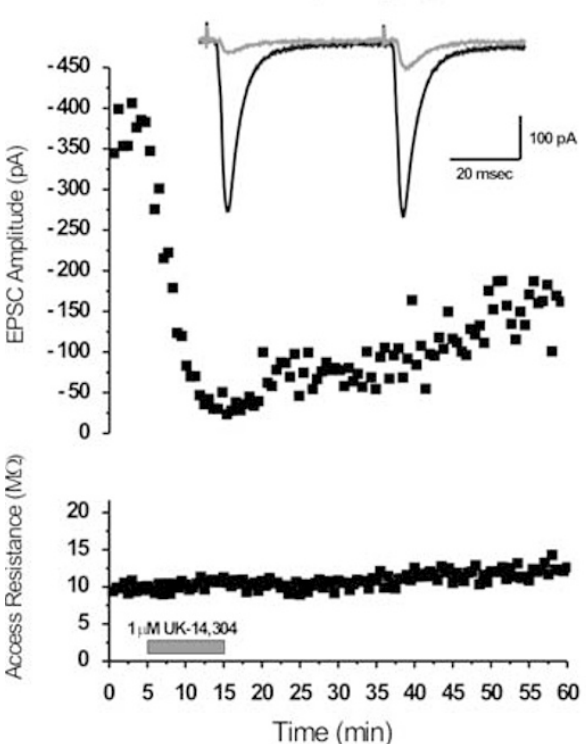

b

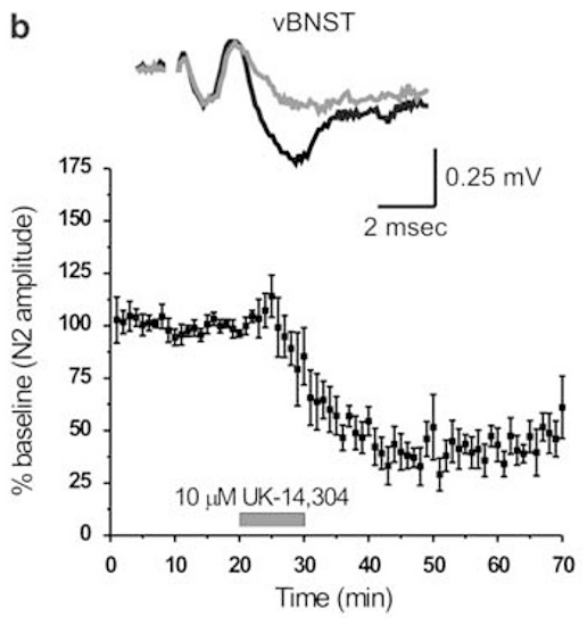

d

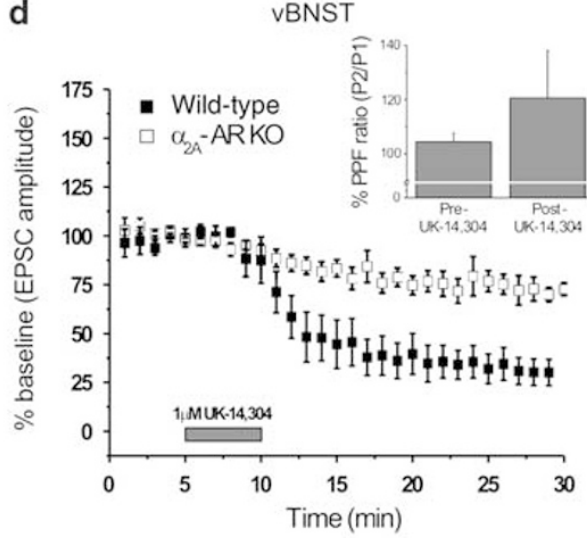

f
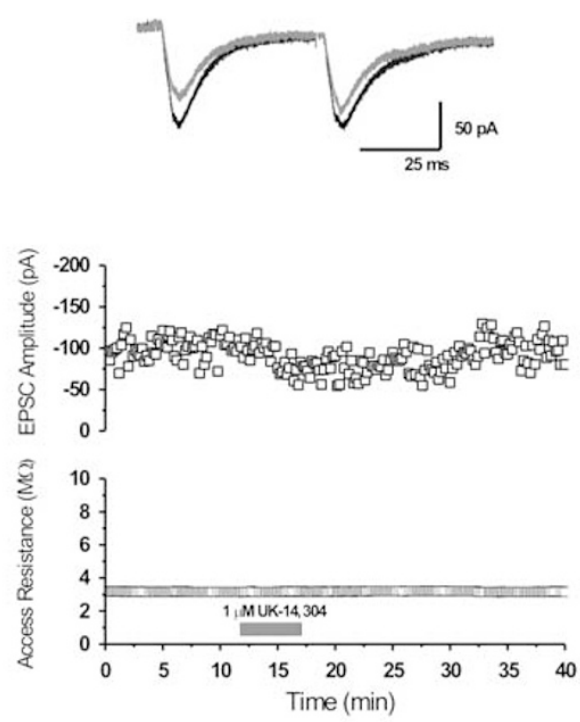

Figure $3 \alpha_{2 A}$-AR activation decreases excitatory synaptic transmission in dBNST and vBNST. (a) Application of the $\alpha_{2}$-AR agonist UK-I4,304 resulted in a decrease in N2 in dBNST in wild-type mice (black squares, $n=3$ ). UK-14,304 had no effect on N2 in dBNST in $\alpha_{2 A}$-AR knockout mice (white squares, $n=7$ ). Inset: representative field potential traces pre- (black) and post-(gray) UK-14,304. (b) Application of UK-I4,304 resulted in a decrease in N2 in vBNST in wild-type mice $(n=5)$. Inset: representative field potential traces pre- (black) and post-(gray) UK-I4,304. (c) Application of UK-I4,304 resulted in a decrease in ABNST EPSC amplitude in wild-type mice $(n=5)$. Inset: paired pulse facilitation ratio (50 ms interstimulus interval) before and after UK-I4,304 application. *statistically significant, $p<0.05$. (d) Application of UK-I4,304 resulted in a decrease in vBNST EPSC amplitude in wild-type mice (dark squares). This effect was reduced in slices taken from $\alpha_{2 A}$-AR knockout mice (open squares). Inset: paired pulse facilitation ratio (50 ms interstimulus interval) before and after UK-I 4,304 application. (e-f) Representative (e) wild-type dBNST EPSC amplitude time course (top) and (f) knockout vBNST EPSC amplitude time course during UK-14,304 application. Bottom time courses show the electrode access resistance during the experiment shown in top time courses. Insets: representative EPSC traces pre- (black) and post-(gray) UK-I4,304. 
the dBNST, the effect of UK-14,304 was dramatically reduced in slices prepared from knockout mouse, suggesting a predominant role for the $\alpha_{2 \mathrm{~A}}$-AR (Figure $3 \mathrm{~d}, \mathrm{f}$ ). Surprisingly, however, a small decrease in transmission was still observed in vBNST $(24.6 \pm 5.1 \%$ depression; $n=6$, $p<0.05$, Figure $3 \mathrm{~d}, \mathrm{f})$, suggesting the involvement of the $\alpha_{2 \mathrm{~B}}-\mathrm{AR}$ and/or $\alpha_{2 \mathrm{C}}-\mathrm{AR}$.

\section{$\beta$-AR Activation Enhances Excitatory Transmission}

Bath application of the $\beta$-AR agonist isoproterenol $(1 \mu \mathrm{M})$ resulted in an increase in the $\mathrm{N} 2$ amplitude in dBNST (131.4. $\pm 8.9 \%, p<0.05, n=7$, Figure $4 \mathrm{a})$. To begin to determine the locus of action of isoproterenol in dBNST, we repeated the $\mathrm{dBNST}$ isoproterenol experiments using singlecell recording techniques. Using whole-cell patch voltage clamp recordings, activation of $\beta$-ARs via isoproterenol $(1-10 \mu \mathrm{M})$ did not enhance the EPSC amplitude (data not shown). However, using sharp microelectrode recording methods, we observed an isoproterenol-induced increase in the EPSP slope ( $118.1 \pm 4.4 \%, p<0.05, n=7$, Figure $4 \mathrm{~b})$. There was no significant concurrent change in paired-pulse facilitation (PPF) (Figure 4b, left inset), input resistance or resting membrane potential (data not shown). The reason for the lack of effect of isoproterenol in the whole-cell patch clamp experiments is unclear, although it is possible that dialysis of the intracellular contents of the postsynaptic cell may be responsible.

Interestingly, isoproterenol had no detectable effect on the N2 in vBNST $(103.2 \pm 3.9 \%, n=7$, Figure 4c). Application of the $\beta$-AR antagonist propranolol $(10 \mu \mathrm{M}$, data not shown) had no effect on the N2 in vBNST, suggesting that the lack of effect of isoproterenol in vBNST was not due to high basal levels of $\beta$-AR activation. This lack of $\beta$-AR effect in vBNST suggests that functional $\beta$-ARs may be lacking in vBNST in the acute slice preparation.

\section{NE Modulation of Excitatory Transmission in dBNST}

Application of the endogenous ligand, NE, resulted in two separate and distinct effects on synaptic transmission in dBNST. In the majority of dBNST recordings (62.2\%), NE application increased the amplitude of the N2 (154.7 $\pm 5.2 \%$ of baseline, $p<0.0001, n=23$, Figure 5a). Interestingly, however, in a subset of recordings in dBNST (37.8\%), NE elicited a long-lasting decrease in the $\mathrm{N} 2$ (initial decrease to $51.1 \pm 6.3 \%$ of baseline, longer lasting depression of $89.5 \pm 5.1 \%$ of baseline, $p<0.05, n=14$, Figure $5 \mathrm{~b}$ ).

To begin to determine the receptor subtypes responsible for these effects of $\mathrm{NE}$ on excitatory transmission, we

Figure $4 \beta$-AR activation results in an increase in excitatory transmission in dBNST, but not vBNST. (a) Application of the $\beta$-AR agonist, isoproterenol, resulted in an increase in N2 in dBNST $(n=7)$. Inset: representative field potential traces pre- (black) and post-(gray) isoproterenol application. (b) Isoproterenol elicited an increase in EPSP slope as measured by sharp microelectrode intracellular recordings in dBNST $(n=7)$. Left inset: paired-pulse facilitation ratios pre- and post-isoproterenol application. Right inset: representative EPSP traces pre- (black) and post-(gray) isoproterenol application. (c) Application of isoproterenol had no effect on N2 in vBNST $(n=7)$. Inset: representative field potential traces pre- (black) and post-(gray) isoproterenol application. assessed the effects of $\beta$-AR antagonists on the response produced. Consistent with the effects of isoproterenol on glutamatergic transmission, we found that the increase in

a

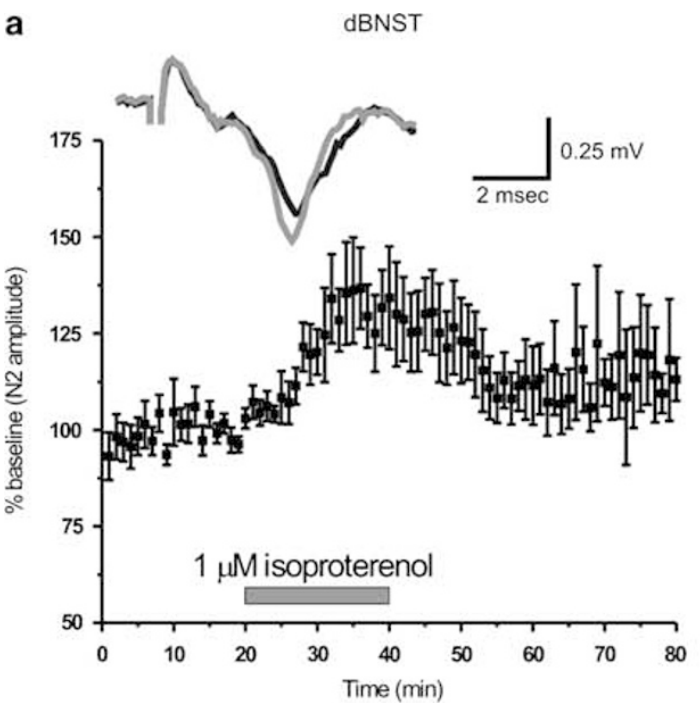

b

dBNST

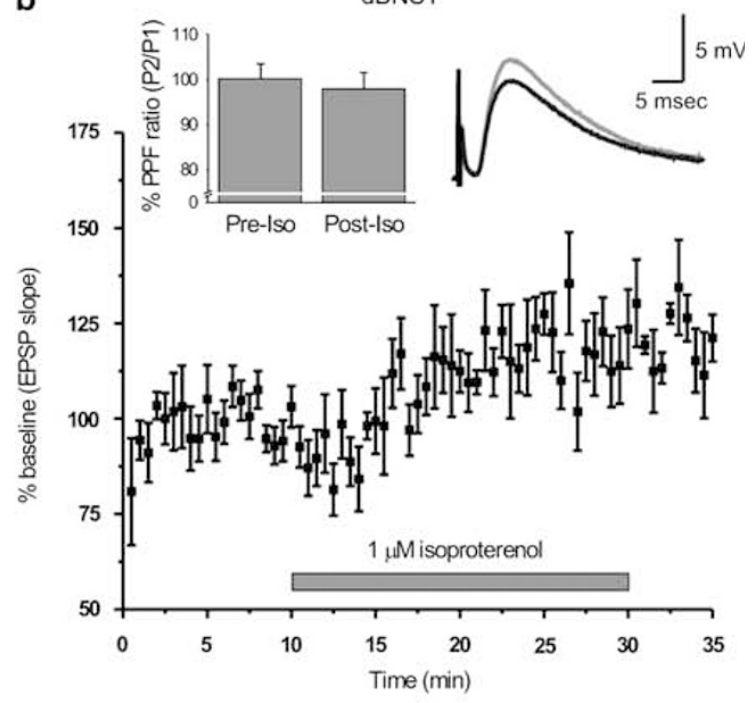

C

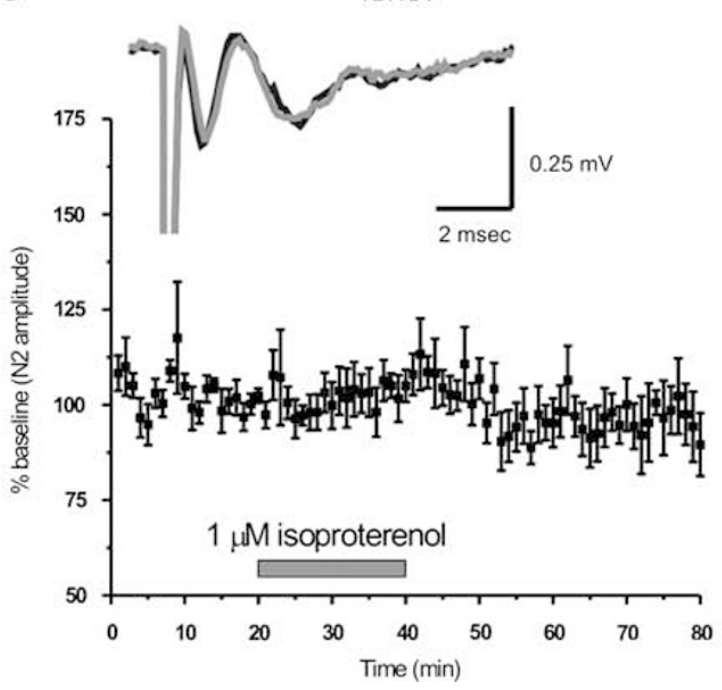



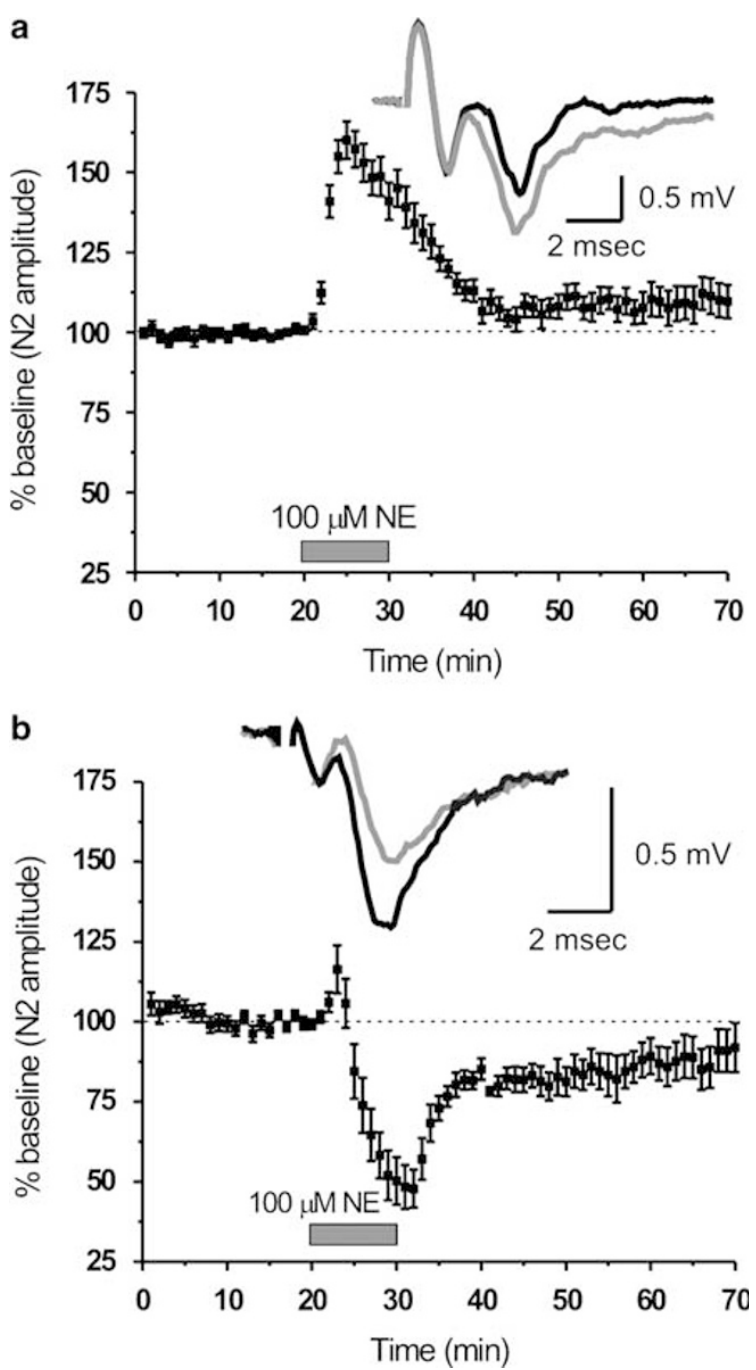

Figure $5 \mathrm{NE}$ induces two distinct effects on excitatory transmission in dBNST. (a) Averaged N2 time course of dBNST experiments where N2 increased during NE application $(n=23)$. Inset: representative field potential traces before (black) and during (gray) NE application. (b) Averaged N2 time course of dBNST experiments where N2 decreased during NE application $(n=14)$. Inset: representative field potential traces before (black) and during (gray) NE application.

the $\mathrm{N} 2$ produced by $\mathrm{NE}$ was at least in part mediated by the $\beta_{2}$-AR. These experiments were performed using a combination of time-interleaved NE experiments across slices as well as dual NE application experiments within slices. Dual application of NE alone to field responses in dBNST led to comparable increases in the $\mathrm{N} 2$ during both applications (1st NE application: $148.5 \pm 11.6 \%, p<0.05$, 2nd $\mathrm{NE}$ application: $133.2 \pm 8.1 \%, p<0.05, n=4$, Figure 6a). Preapplication of timolol ( $\beta_{1}-$ and $\beta_{2}$-AR antagonist, $\left.10 \mu \mathrm{M}\right)$ resulted in a robust inhibition of the NE-induced increase in the N2 $(109.7 \pm 4.6 \%$ of baseline, $n=4$, Figure $6 \mathrm{~b})$. Pretreatment with betaxolol $\left(10 \mu \mathrm{M}\right.$, specific $\beta_{1}$-AR antagonist $)$ had essentially no effect on the NE-induced increase in the $\mathrm{N} 2$ amplitude (169.8 $\pm 14.9 \%$ of baseline, $p<0.05, n=3$, Figure 6c). It should be noted that this concentration of betaxolol was sufficient to block isoproterenol-induced phosphorylation of the GluR1 subunit of the AMPAR in hippocampal slices (Vanhoose and Winder, 2003). Pretreat- ment with ICI-118,551 (10 $\mu \mathrm{M}$, specific $\beta_{2}$-AR antagonist) blunted the increase in the $\mathrm{N} 2$ seen with $\mathrm{NE}$ to a similar degree as timolol $(123.6 \pm 4.7 \%$ of baseline, $p<0.05, n=3$, Figure 6d).

In addition, we also assessed the effects of NE on the N2 in $\mathrm{dBNST}$ in slices prepared from the $\alpha_{2 \mathrm{~A}}$-AR knockout mouse. Interestingly, we find that, in these slices, NE at a concentration of $100 \mu \mathrm{M}$ has no detectable effect on the N2 $(n=5)$, suggesting that this receptor participates both in the NE-induced depression of the $\mathrm{N} 2$ response and the enhancement of the N2 response (Figure 7a, b). Consistent with these data, in wild-type mouse dBNST preapplication of the $\alpha_{2}$-AR antagonist yohimbine $(10 \mu \mathrm{M})$ also resulted in a marked inhibition of the NE-induced responses (117.0 $\pm 9.2 \%$ of baseline, $p=0.17$ (compared to baseline), $n=6$, Figure $7 \mathrm{c}$ ).

\section{NE Modulation of Excitatory Transmission in vBNST}

Surprisingly, in contrast to the multiple effects of NE seen in dBNST, in vBNST, application of NE only evoked a decrease in the $\mathrm{N} 2$ amplitude $(62.2 . \pm 10.4 \%$ of baseline, $p<0.05$, $n=5$, Figure 8a). In vBNST field recordings from slices prepared from $\alpha_{2 \mathrm{~A}}$-AR knockout mice, application of $\mathrm{NE}$ $(100 \mu \mathrm{M})$ resulted in a much smaller, although still significant, effect on transmission $(93.8 \pm 1.7 \%, p<0.05, n=6$, Figure $8 \mathrm{~b})$.

\section{NE Effect on the N2 in dBNST Depends on $\beta$-AR Activation}

To begin to address what underlies the variability of the NE effect on glutamatergic transmission in dBNST, we have performed experiments to correlate the level of specific receptor activity with the NE effect. Based on the distinct responses to NE and isoproterenol between dBNST and vBNST, we hypothesized that variability in the participation of $\beta_{2}$-ARs, which appear to be necessary for the NE-induced increase in the N2, may be at least partially responsible for the divergent responses to $\mathrm{NE}$ the we have recorded. In order to test this idea, we performed experiments in which $\mathrm{NE}$ was applied and then followed $40 \mathrm{~min}$ later with the $\beta$ AR agonist isoproterenol. In dBNST slices where NE decreased the $\mathrm{N} 2$, subsequent application of isoproterenol elicited only a small nonsignificant increase in the N2 amplitude (109.7 $\pm 3.9 \%, n=5$, Figure 9b). Conversely, when NE increased the $\mathrm{N} 2$, subsequent application of isoproterenol led to a robust increase in transmission $(143.4 \pm 12.7 \%, p<0.05, n=4$, Figure 9a). The NE effect and the magnitude of the isoproterenol effect are significantly correlated with one another (Pearson correlation analysis, $r^{2}=0.56, p<0.02$, Figure 9c).

\section{DISCUSSION}

It is clear from the behavioral literature that intra-BNST actions of noradrenergic receptors are critical in mediating stress-induced reinstatement behavior; however, the mechanisms underlying these effects are unknown. We have shown that activation of ARs by either NE or specific noradrenergic receptor agonists can robustly modulate excitatory synaptic transmission in the BNST. We find that 

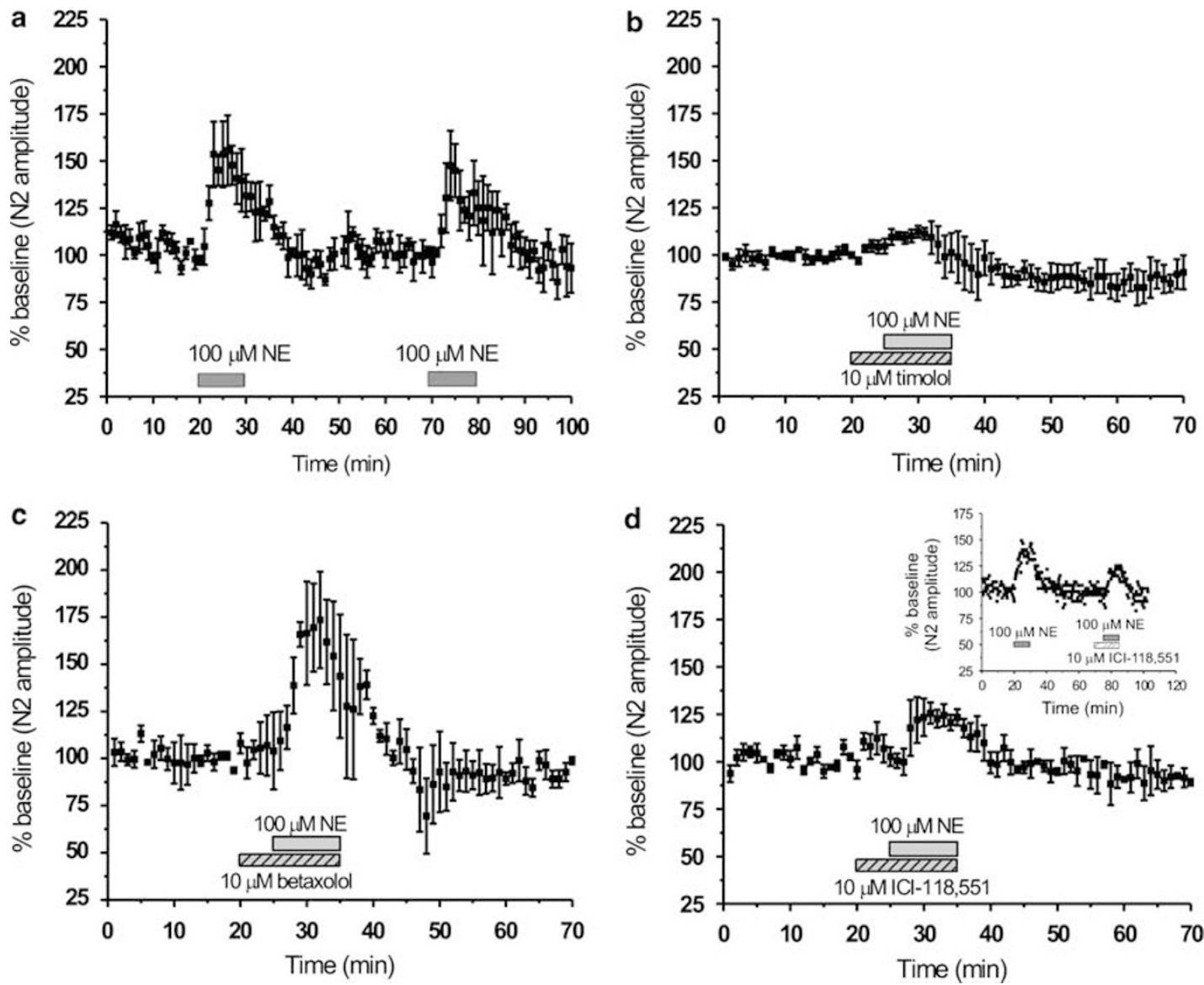

Figure 6 Dependence of NE actions in dBNST on $\beta_{2} A R s$. (a) Dual application of NE (I00 $\left.\mu \mathrm{M}\right)$ resulted in comparable increases in N2 in dBNST field potentials during both applications $(n=4)$. (b) In time-interleaved experiments, preapplication of the nonspecific $\beta$-AR antagonist timolol blocked the NE-induced increase in N2 in dBNST $(n=4)$. (c) In time-interleaved experiments, preapplication of the $\beta_{1}$-AR antagonist betaxolol had no effect on the NE-induced increase in N2 in dBNST $(n=3)$. (d) Preapplication of the $\beta_{2}$-AR antagonist ICl- I I 8,55 I blunted the NE-induced increase in N2 in dBNST $(n=3$ (2 time-interleaved experiments + I dual NE-application experiments)). Inset: time course of a NE followed by ICl- I I 8,55 I/NE experiment.

specific activation of the $\beta$-AR via isoproterenol results in an increase in transmission, while specific activation of the $\alpha_{2}$-AR via UK-14,304 results in a decrease in transmission. In addition, we find that NE can induce a $\beta_{2^{-}}$and $\alpha_{2}$-ARmediated increase in glutamatergic synaptic transmission, an effect seen frequently in dBNST but never in vBNST. An NE-induced decrease in glutamatergic responses is seen less frequently in dBNST but is the only effect of NE observed on glutamatergic responses in vBNST. Additionally, we find that in slices where NE elicits an increase in glutamatergic responses, subsequent activation of the $\beta$-AR also elicits a robust increase in glutamatergic responses. However, in slices where $\mathrm{NE}$ elicits a decrease in glutamatergic responses, subsequent activation of the $\beta$-AR has very little effect, suggesting that the activity of the $\beta$-AR correlates with the effect of NE on excitatory transmission in BNST.

\section{$\alpha_{2 \mathrm{~A}^{-}}$and $\beta$-AR Agonists Produce Opposing Regulation of Excitatory Synaptic Transmission}

Intra-BNST injections of $\alpha_{2}$-AR agonists block stressinduced reinstatement to drug-seeking (Delfs et al, 2000; Wang et al, 2001). We have shown that activation of $\alpha_{2}$-ARs by specific $\alpha_{2}$-AR agonists results in a decrease in excitatory transmission in both dBNST and vBNST. Further, in slices prepared from $\alpha_{2 \mathrm{~A}}$-AR knockout mice, UK-14,304 had no effect on transmission in dBNST suggesting a subtype specificity of this effect for the $\alpha_{2 \mathrm{~A}}$-AR. In vBNST, a modest response remained, suggesting the additional potential involvement of $\alpha_{2 \mathrm{~B}}$ and/or $\alpha_{2 \mathrm{C}}$ receptors. Further experiments will be required to examine this hypothesis, but these data suggest that inhibition of glutamatergic transmission in BNST by $\alpha_{2 \mathrm{~A}}-\mathrm{AR}$ activation may be one potential mechanism by which $\alpha_{2}$-AR agonists may mediate effects on behavior.

Similar to injections of $\alpha_{2}$-AR agonists, intra-BNST injections of $\beta$-AR antagonists also prevent stress-induced reinstatement to drug-seeking (Delfs et al, 2000; Leri et al, 2002). We have demonstrated that application of both the $\beta$ AR agonist isoproterenol as well as NE can elicit an increase in glutamatergic responses in $\mathrm{dBNST}$, but not vBNST. The increase in glutamatergic transmission we see in response to $\mathrm{NE}$ is mediated primarily by the $\beta_{2}-\mathrm{AR}$. This is surprising since in other brain regions noradrenergic enhancement of transmission is mediated by the $\beta_{1}$-AR (Pisani et al, 2003; Winder et al, 1999). As the $\beta_{2}$-AR undergoes ligand binding-induced desensitization more readily than both the $\beta_{1}{ }^{-}$and the $\alpha_{2}$-ARs (Atkinson and Minneman, 1992; Suzuki et al, 1992), the specificity of increasing transmission with the $\beta_{2}$-AR in BNST may provide a protective 

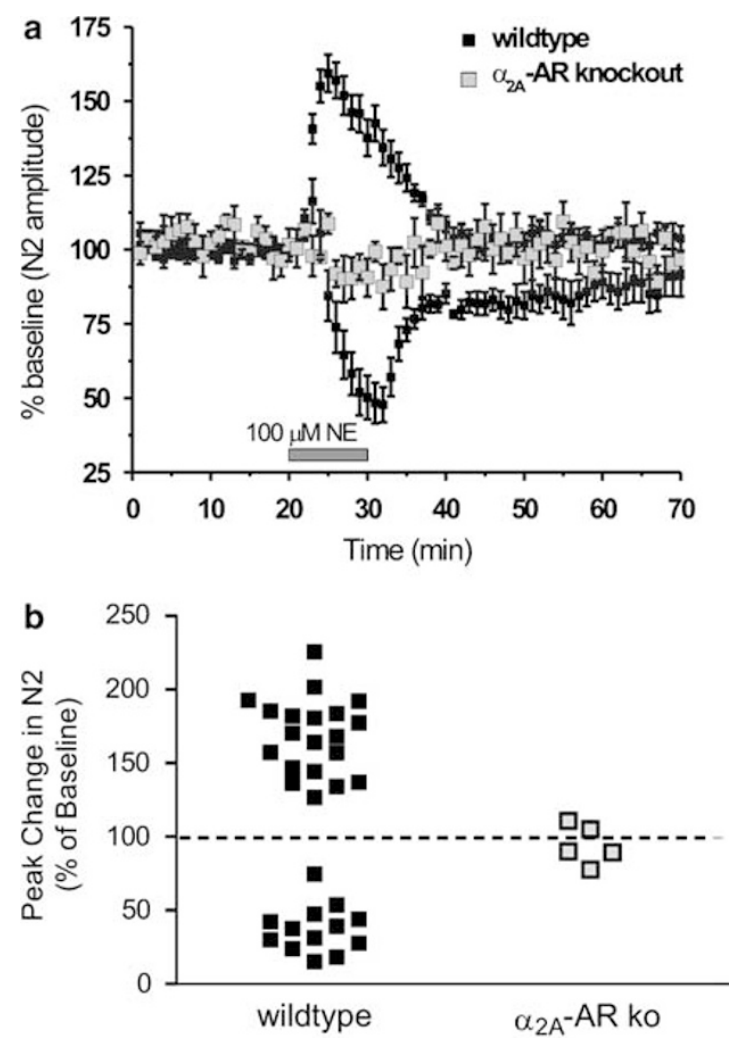

C

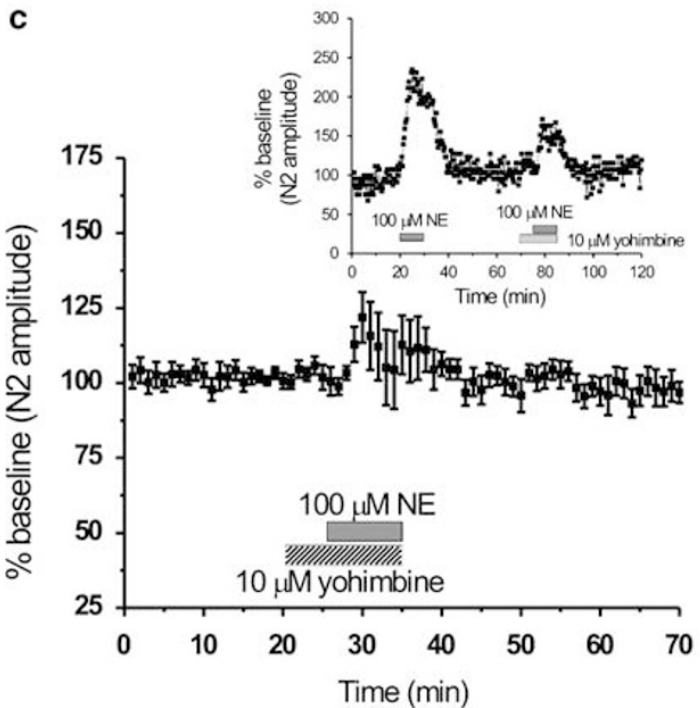

Figure 7 Dependence of NE actions in dBNST on $\alpha_{2 A}$-ARs. (a) Effects of NE $(100 \mu \mathrm{M})$ on the N2 in dBNST in $\alpha_{2 A}$-AR knockout mouse. Black time courses are re-plots of wild-type data from Figure 5. (b) Scatter-plot of peak effects of NE in wild type (filled squares) and $\alpha_{2 A}$-AR knockout mice (open squares). (c) Preapplication of the $\alpha_{2}$-AR antagonist yohimbine blunted the NE-induced increase in N2 in dBNST ( $n=6$ (3 timeinterleaved experiments +3 dual-NE application experiments)). Inset: representative time course of an $\mathrm{NE}$ followed by yohimbine/NE experiment.

mechanism against overstimulation of adrenergic signaling by reducing availability of the $\beta_{2}$-AR while maintaining the $\alpha_{2}-\mathrm{AR}$, which will further decrease glutamatergic input to the BNST. At present, it is unclear by what mechanism $\beta_{2}$-AR activation regulates excitatory transmission. Since the enhancement of excitatory transmission was not a

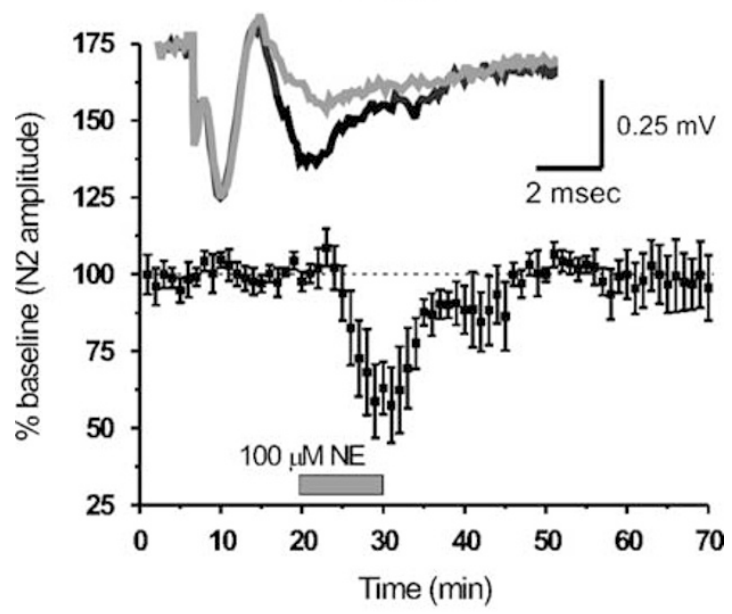

b $\quad \alpha_{2 A}$-AR ko

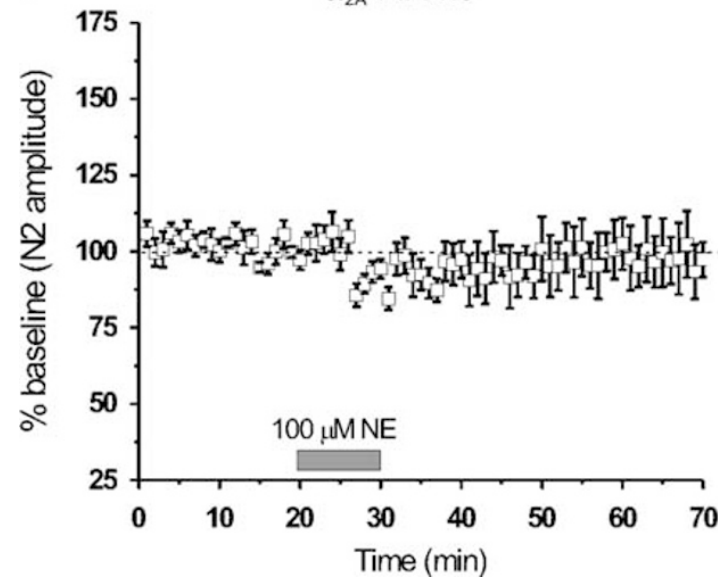

Figure 8 (a) Averaged time course of effect of NE application ( I $00 \mu \mathrm{M})$ on N2 in vBNST $(n=5)$. Inset: representative field potential traces before (black) and during (gray) NE application. (b) Averaged time course of effect of NE application (100 $\mu \mathrm{M})$ on N2 in VBNST in $\alpha_{2 A}$-AR knockout mice (white squares, $n=6$ ).

observed under the whole-cell patch clamp recording configuration, one possibility is that this represents a postsynaptic action of isoproterenol. Dialysis of critical postsynaptic contents or the replacement of potassium with cesium in the electrode filling solution are potential explanations consistent with this idea.

\section{NE Both Enhances and Depresses Excitatory Transmission in BNST}

Similar to the effects of specific agonists of noradrenergic receptors, we find that application of the endogenous agonist NE can both enhance and depress glutamatergic transmission. In vBNST, only depression was observed. This depression was markedly reduced in the $\alpha_{2 \mathrm{~A}}$-AR knockout mouse and was mimicked by $\alpha_{2 \mathrm{~A}}-\mathrm{AR}$ specific agonists, suggesting that it is mediated primarily via the $\alpha_{2 \mathrm{~A}}-\mathrm{AR}$, and to some degree the $\alpha_{2 \mathrm{~B}}$ and/or $\alpha_{2 \mathrm{C}}$-ARs.

In the dBNST, both augmentation and depression of glutamatergic transmission by NE was observed. As mentioned above, the augmentation was markedly reduced 

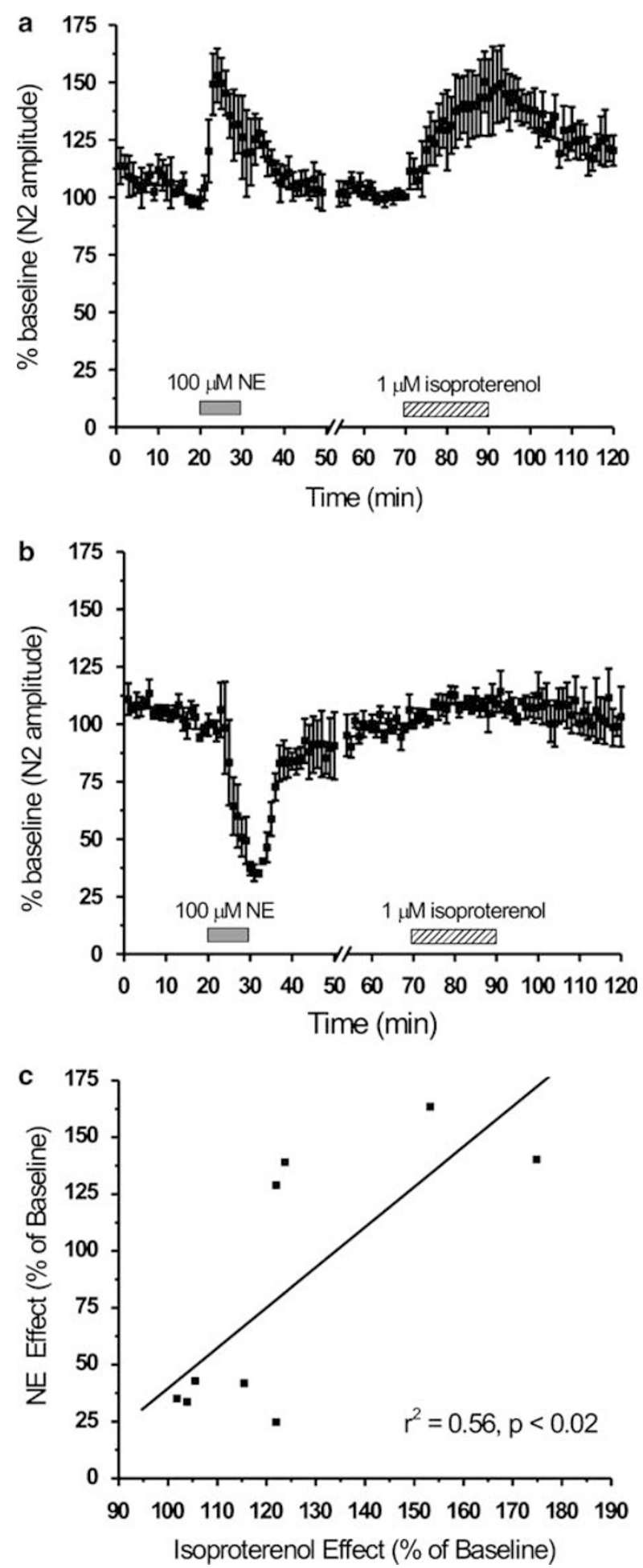

Figure 9 NE effect in $\mathrm{dBNST}$ can be correlated with magnitude of effect of $\beta$-AR activation. (a) When NE elicits an increase in N2 in dBNST, subsequent application of isoproterenol elicits a robust increase in N2 $(n=4)$. (b) When NE elicits a decrease in N2 in dBNST, subsequent application of isoproterenol elicits very little to no increase in N2 $(n=5)$. (c) Correlation plot of NE effect vs the isoproterenol effect.

by $\beta_{2}$-AR antagonists. In addition, we also found that a correlation may be drawn between the effect of $\mathrm{NE}$ and the effect of isoproterenol, suggesting that the functional state of the $\beta$-AR may mediate the NE modulation of excitatory transmission in BNST. In slices where NE elicited an increase in transmission in dBNST, subsequent application of isoproterenol resulted in a substantial and long-lasting increase in transmission, whereas in slices where $\mathrm{NE}$ resulted in a decrease in transmission, subsequent application of isoproterenol had very little to no effect. These data suggest that these different responses to NE in dBNST are tied to the functional state of the $\beta$-AR. Multiple mechanisms could regulate the functional state of this receptor, and future studies will need to focus on this issue.

Surprisingly, we also found that $\alpha_{2}$-ARs contribute to the augmentation of glutamatergic transmission in dBNST. First, we found that the $\alpha_{2}$-AR antagonist yohimbine reduced the enhancing action of NE in dBNST. Second, we found that this augmentation was not observed in $\alpha_{2 \mathrm{~A}^{-}}$ AR knockout mice. Several pieces of data suggest that the $\alpha_{2}$-AR enhances glutamatergic transmission by an interaction with $\beta$-ARs. First, enhancement of glutamatergic transmission was not observed to a significant degree with $\alpha_{2}$-AR agonists alone, either in extracellular or intracellular recordings. Second, NE does not enhance glutamatergic transmission in slices in which $\beta$-AR agonists fail to enhance transmission. These findings are reminiscent of other examples in the literature where Gi/o-linked receptors have been shown to facilitate the actions of Gs-linked receptors, such as was recently shown for D1 and D2 dopamine receptors in the nucleus accumbens (Hopf et al, 2003 ), and the $\alpha_{2}$-AR and $\beta$-AR in hippocampus (Andrade, 1993).

\section{CONCLUSIONS}

Our data suggest that NE in the BNST can have variable effects on BNST function, which is consistent with the current field of literature. As measured by in vivo microdialysis, NE elicits a decrease in extracellular glutamate levels in the BNST (Forray et al, 1999). In in vivo single-unit extracellular recordings from anesthetized rats, $\mathrm{NE}$ application results in a variety of effects on BNST neuron firing rates, with the majority of cells recorded from undergoing a decrease in firing rate and a smaller subset undergoing an increase in firing rate (Casada and Dafny, 1993). Additionally, early extracellular recordings from BNST slices showed that NE leads to an $\alpha_{2}$-AR mediated decrease in a field potential (Matsui and Yamamoto, 1984). We have extended these findings and have shown that $\mathrm{NE}$ can elicit qualitatively distinct actions on evoked excitatory synaptic transmission in BNST. In future studies, it will be important to determine whether variability of the $\beta_{2^{-}}$ adrenergic receptor responses reported reflects cellular variability within the BNST, which is a heterogeneous cell population.

Behavioral data indicate that $\alpha_{2}$ - and $\beta$-ARs within the anterolateral BNST play opposing roles in regulating stressdrug abuse interactions (Delfs et al, 2000; Leri et al, 2002; Wang et al, 2001). Here we show at the cellular level in the BNST that a similar antagonistic relationship between these two receptors exists in modulating glutamatergic input to BNST neurons. $\beta$-AR activation increases the effects of glutamatergic drive onto BNST neurons, likely increasing BNST output, while $\alpha_{2}$-AR activation decreases this drive 
and likely decreases BNST output. The BNST projects both to stress and reward centers of the brain (Cullinan et al, 1993; Dong and Swanson, 2004; Georges and Aston-Jones, 2002), and the data presented here suggest that norepinephrine can modulate excitatory transmission within the BNST and therefore its output, which may provide a potential mechanism by which noradrenergic receptor ligands can regulate behavioral stress-drug interactions.

\section{ACKNOWLEDGEMENTS}

This work was supported by an NIAAA INIA pilot grant (U01-AA13541) and Whitehall Foundation (DGW), DA16456 (REE), MH58921 (RDB, VS). We would also like to thank Dr's Lee Limbird and Brian Kobilka for generous donation of the $\alpha_{2 \mathrm{~A}}$-AR knockout mice, Dr Marc Caron for the NET knockout mice, and Amanda Vanhoose for reading previous versions of this manuscript.

\section{REFERENCES}

Andrade R (1993). Enhancement of beta-adrenergic responses by $\mathrm{G}_{\mathrm{i}}$-linked receptors in rat hippocampus. Neuron 10: 83-88.

Atkinson BN, Minneman KP (1992). Preferential desensitization of beta- versus alpha 2-adrenergic receptors accelerates loss of response to norepinephrine in primary glial cultures. $\mathrm{Mol}$ Pharmacol 41: 688-694.

Brown SA, Vik PW, Patterson TL, Grant I, Schuckit MA (1995). Stress, vulnerability and adult alcohol relapse. J Stud Alcohol 56: 538-545.

Casada JH, Dafny N (1993). Responses of neurons in bed nucleus of the stria terminalis to microiontophoretically applied morphine, norepinephrine and acetylcholine. Neuropharmacology 32: 279-284.

Cordingley GE, Weight FF (1986). Non-cholinergic synaptic excitation in neostriatum: pharmacological evidence for mediation by a glutamate-like transmitter. $\mathrm{Br} J$ Pharmacol 88: 847-856.

Cullinan WE, Herman JP, Watson SJ (1993). Ventral subicular interaction with the hypothalamic paraventricular nucleus: evidence for a relay in the bed nucleus of the stria terminalis. J Comp Neurol 332: 1-20.

Delfs JM, Zhu Y, Druhan JP, Aston-Jones G (2000). Noradrenaline in the ventral forebrain is critical for opiate withdrawal-induced aversion. Nature 403: 430-434.

Dong HW, Swanson LW (2004). Organization of axonal projections from the anterolateral area of the bed nuclei of the stria terminalis. J Comp Neurol 468: 277-298.

Egli RE, Winder DG (2003). Dorsal and ventral distribution of excitable and synaptic properties of neurons of the bed nucleus of the stria terminalis. J Neurophysiol 90: 405-414.

Erb S, Hitchcott PK, Rajabi H, Mueller D, Shaham Y, Stewart J (2000). Alpha-2 adrenergic receptor agonists block stressinduced reinstatement of cocaine seeking. Neuropsychopharmacology 23: 138-150.

Forray MI, Bustos G, Gysling K (1999). Noradrenaline inhibits glutamate release in the rat bed nucleus of the stria terminalis: in vivo microdialysis studies. J Neurosci Res 55: 311-320.

Franklin KBJ, Paxinos G (1997). The Mouse Brain in Stereotaxic Coordinates. Academic Press: New York.

Freedman LJ, Shi C (2001). Monoaminergic innervation of the macaque extended amygdala. Neuroscience 104: 1067-1084.

Georges F, Aston-Jones G (2001). Potent regulation of midbrain dopamine neurons by the bed nucleus of the stria terminalis. J Neurosci 21: RC160.
Georges F, Aston-Jones G (2002). Activation of ventral tegmental area cells by the bed nucleus of the stria terminalis: a novel excitatory amino acid input to midbrain dopamine neurons. J Neurosci 22: 5173-5187.

Hopf FW, Cascini MG, Gordon AS, Diamond I, Bonci A (2003). Cooperative activation of dopamine D1 and D2 receptors increases spike firing of nucleus accumbens neurons via G-protein betagamma subunits. J Neurosci 23: 5079-5087.

Le AD, Harding S, Juzytsch W, Watchus J, Shalev U, Shaham Y (2000). The role of corticotrophin-releasing factor in stressinduced relapse to alcohol-seeking behavior in rats. Psychopharmacology (Berlin) 150: 317-324.

Leri F, Flores J, Rodaros D, Stewart J (2002). Blockade of stressinduced but not cocaine-induced reinstatement by infusion of noradrenergic antagonists into the bed nucleus of the stria terminalis or the central nucleus of the amygdala. J Neurosci 22: 5713-5718.

Malenka RC, Kocsis JD (1988). Presynaptic actions of carbachol and adenosine on corticostriatal synaptic transmission studied in vitro. J Neurosci 8: 3750-3756.

Matsui H, Yamamoto C (1984). The possible involvement of adenylate cyclase inhibition in the field potential suppression through alpha-2 adrenergic receptors in the bed nucleus of the stria terminalis. Brain Res 293: 187-190.

Pisani A, Bonsi P, Centonze D, Martorana A, Fusco F, Sancesario G et al (2003). Activation of betal-adrenoceptors excites striatal cholinergic interneurons through a cAMP-dependent, protein kinase-independent pathway. J Neurosci 23: 5272-5282.

Rainnie DG (1999). Neurons of the bed nucleus of the stria terminalis (BNST). Electrophysiological properties and their response to serotonin. Ann NY Acad Sci 877: 695-699.

Savchenko V, Sung U, Blakely RD (2003). Cell surface trafficking of the antidepressant-sensitive norepinephrine transporter revealed with an ectodomain antibody. Mol Cell Neurosci 24: $1131-1150$.

Shaham Y, Erb S, Stewart J (2000). Stress-induced relapse to heroin and cocaine seeking in rats: a review. Brain Res Brain Res Rev 33: 13-33.

Sinha R, Catapano D, O’Malley S (1999). Stress-induced craving and stress response in cocaine dependent individuals. Psychopharmacology (Berlin) 142: 343-351.

Suzuki T, Nguyen CT, Nantel F, Bonin H, Valiquette M, Frielle T et al (1992). Distinct regulation of beta 1- and beta 2-adrenergic receptors in Chinese hamster fibroblasts. Mol Pharmacol 41: 542-548.

Takagi M, Yamamoto C (1978). Suppressing action of cholinergic agents on synaptic transmissions in the corpus striatum of rats. Exp Neurol 62: 433-443.

Vanhoose AM, Winder DG (2003). NMDA and beta1-adrenergic receptors differentially signal phosphorylation of glutamate receptor type 1 in area CA1 of hippocampus. J Neurosci 23: 5827-5834.

Wang X, Cen X, Lu L (2001). Noradrenaline in the bed nucleus of the stria terminalis is critical for stress-induced reactivation of morphine-conditioned place preference in rats. Eur J Pharmacol 432: $153-161$.

Weitlauf C, Egli RE, Grueter BA, Winder DG (2004). Highfrequency stimulation induces ethanol sensitive long-term potentiation at glutamatergic synapses in the dorsolateral bed nucleus of the stria terminalis. J Neurosci 24: 5741-5747.

Winder DG, Martin KC, Muzzio IA, Rohrer D, Chruscinski A, Kobilka B et al (1999). ERK plays a regulatory role in induction of LTP by theta frequency stimulation and its modulation by beta-adrenergic receptors. Neuron 24: 715-726.

Woulfe JM, Flumerfelt BA, Hrycyshyn AW (1990). Efferent connections of the A1 noradrenergic cell group: a $\mathrm{DBH}$ immunohistochemical and PHA-L anterograde tracing study. Exp Neurol 109: 308-322. 